\title{
Effects of early-life environment and epigenetics on cardiovascular disease risk in children: highlighting the role of twin studies
}

\author{
Cong Sun', David P. Burgner2,3, Anne-Louise Ponsonby ${ }^{1,3}$, Richard Saffery ${ }^{3,4}$, Rae-Chi Huang ${ }^{5}$, Peter J. Vuillermin ${ }^{1,6,7}$, \\ Michael Cheung ${ }^{3,8}$ and Jeffrey M. Craig ${ }^{3,9}$
}

Cardiovascular disease (CVD) is the leading cause of death worldwide and originates in early life. The exact mechanisms of this early-life origin are unclear, but a likely mediator at the molecular level is epigenetic dysregulation of gene expression. Epigenetic factors have thus been posited as the likely drivers of early-life programming of adult-onset diseases. This review summarizes recent advances in epidemiology and epigenetic research of CVD risk in children, with a particular focus on twin studies. Classic twin studies enable partitioning of phenotypic variance within a population into additive genetic, shared, and nonshared environmental variances, and are invaluable in research in this area. Longitudinal cohort twin studies, in particular, may provide important insights into the role of epigenetics in the pathogenesis of CVD. We describe candidate gene and epigenome-wide association studies (EWASs) and transgenerational epigenetic inheritance of CVD, and discuss the potential for evidence-based interventions. Identifying epigenetic changes associated with CVD-risk biomarkers in children will provide new opportunities to unravel the underlying biological mechanism of the origins of CVD and enable identification of those at risk for early-life interventions to alter the risk trajectory and potentially reduce CVD incidence later in life.

C ardiovascular disease (CVD) is the leading cause of death worldwide and carries a huge economic burden (1). Early identification of individuals at increased risk of CVD is fundamental to developing effective prevention. However, known environmental and genetic factors explain only a small proportion of the variability in CVD risk, a major obstacle to prevention (2). This partly reflects the research focus on adulthood rather than early life, a critical but poorly understood period in the pathogenesis of CVD.

The development of atherosclerosis, the underlying pathology of CVD, begins in early life, in some cases before birth (3). An adverse intrauterine environment and impaired fetal growth have been suggested to contribute to the early development of atherosclerosis, with a long latency period between these and other exposures and adult CVD (4). The mechanisms contributing to early CVD risk, however, are unclear. A likely mediator at the molecular level is epigenetic dysregulation of gene expression. Epigenetic factors show interindividual variability at birth that may be stable throughout the life course and have been posited as the likely drivers of early-life programming of adult-onset diseases (5).

Although several recent articles have reviewed current knowledge regarding the role of epigenetics in the pathogenesis of CVD $(2,6)$, evidence regarding the dysregulation of the early-life epigenome (the sum total of genomic epigenetic marks such as DNA methylation) in response to known CVD risk factors has not been summarized. Here, we summarize recent literature on the epidemiology and epigenetics of CVD risk in children, with a particular focus on twin studies. We highlight the use of CVD risk biomarkers in the pediatric populations in risk prediction and targeting of therapy, as well as in the development of interventions that may modulate subsequent risk of CVD.

\section{EARLY-LIFE ORIGINS OF CVD}

In the past two decades, evidence has accumulated that earlylife risk factors may influence the development of atherosclerosis and subsequent CVD risk in adulthood. Atherosclerosis is a progressive process. The accumulation of lipids in the intima of arteries results in fatty streaks that may develop into atherosclerotic plaques, ultimately causing reduction in blood flow to critical organs, especially if the plaques rupture. Autopsy studies have shown a higher frequency of fatty-streak lesions detected in the arteries of human fetuses from mothers who smoked heavily in pregnancy or those with hypercholesterolemia as compared with those unexposed (7). Furthermore, fatty streaks detected in aortas in children as young as $3 \mathrm{y}$ progress to atherosclerotic plaques by young adulthood (8).

The hypothesis, suggested by Barker and colleagues, that initially focused on adverse maternal environment, low birth

\footnotetext{
'Environmental and Genetic Epidemiology Research Group, Public Health Genes and Environment Theme, Murdoch Childrens Research Institute, Royal Children's Hospital, Melbourne, Australia; ${ }^{2}$ Infection and Immunology Theme, Murdoch Childrens Research Institute, Royal Children's Hospital, Melbourne, Australia; ${ }^{3}$ Department of Paediatrics, University of Melbourne, Melbourne, Australia; ${ }^{4}$ Cancer, Disease and Developmental Epigenetics Group, Cell Biology, Development and Disease Theme, Murdoch Childrens Research Institute, Royal Children's Hospital, Melbourne, Australia; ${ }^{5}$ School of Paediatrics and Child Health, School of Medicine and Pharmacology, University of Western Australia, Perth, Australia; ${ }^{6} \mathrm{C}$ hild Health Research Unit, Barwon Health, Geelong, Australia; ${ }^{7}$ School of Medicine, Deakin University, Geelong, Australia; ${ }^{8} \mathrm{Critical}$ Care and Neurosciences Theme, Murdoch Childrens Research Institute, Royal Children's Hospital, Melbourne, Australia; 'arly Life Epigenetics Group, Public Health Genes and Environment Theme, Murdoch Childrens Research Institute, Royal Children's Hospital, Melbourne, Australia. Correspondence: Cong Sun (cong.sun@mcri.edu.au)
} 
weight, and CVD risk (9) has evolved into the "Developmental Origins of Health and Disease" hypothesis. This emphasizes the critical early-life period when nutrition and other environmental stimuli may influence developmental pathways and induce long-lasting changes in metabolism and cardiovascular health (4), although the causal relationships and underlying mechanisms remain controversial.

Pediatric studies on environmental factors that may influence risk of CVD have investigated a range of CVD biomarkers (10). A range of CVD risk factors and vascular health biomarkers that have been measured in childhood are summarized in the Table 1. Vascular endothelial dysfunction begins in early life and is a central pathological status in the early development of atherosclerosis (11). The role of biomarkers of endothelial function in CVD development has thus been investigated. In line with this, early-life CVD risk factors, in particular childhood obesity, are strongly associated with endothelial dysfunction and the development of atherosclerosis and CVD (12). More important, there is emerging evidence that childhood CVD risk factors, such as hypertriglyceridemia, are independently predictive of adult CVD (13), although studies have been relatively underpowered and larger sample sizes are warranted (14). There is also strong evidence that CVD risk factors in childhood are associated with CVD precursor conditions or intermediate vascular end points in adulthood (e.g., diabetes, hypertension, and larger carotid intima-media thickness) (15). Clustering of CVD risk factors, which imparts an even greater risk than the sum of the individual risk factors in adults (16), also occurs in childhood $(17,18)$. This clustering of CVD risk factors not only tracks from childhood into adult life (19) but

Table 1. CVD-risk biomarkers studied in children

\begin{tabular}{ll}
\hline Biomarker & Parameters measured \\
\hline $\begin{array}{l}\text { Measures of vascular health } \\
\text { Arterial distensibility, compliance, elastic } \\
\text { modulus, and pulse wave velocity }\end{array}$ & Arterial stiffness \\
Flow-mediated vasodilatation & Endothelial function \\
High-sensitivity C-reactive protein & Systemic inflammation \\
Serum ICAM-1 and VCAM-1 & Endothelial function \\
Retinal arteriolar and venular caliber & Diameter of \\
& microvasculature \\
Traditional CVD risk factors & \\
Adiposity & $\begin{array}{l}\text { BMI, waist circumference, } \\
\text { skinfold thickness, body } \\
\text { fatness, ponderal index, } \\
\text { and so on }\end{array}$ \\
Serial weight gain & $\begin{array}{l}\text { Weight for age at birth, } \\
\text { and so on }\end{array}$ \\
Systolic and diastolic blood pressure & Blood pressure \\
Serum HDL cholesterol, total cholesterol & Dyslipidemia \\
Serum apolipoprotein B & Dyslipidemia \\
HOMA-IR & Insulin resistance \\
\hline
\end{tabular}

CVD, cardiovascular disease; HDL, high-density lipoprotein; HOMA-IR, homeostatic model assessment for insulin resistance; ICAM-1, intercellular adhesion molecule-1; VCAM-1,

vascular cell adhesion molecule-1. is also associated with the antecedents of increased blood pressure and skinfold thickness in early infancy (18).

By the preschool years, low-birth-weight infants have early signs of impaired vascular health, including thicker carotid intima-media thickness (3) and increased arterial stiffness (20). These infants also have higher levels of CVD risk factors such as adiposity, insulin resistance, and dyslipidemia as compared with those with normal birth weight (21). The relationship between compromised intrauterine nutrition and low birth weight, however, is not straightforward, and other adiposity measures such as ponderal index (weight divided by length cubed) and abdominal circumference at birth may be better early-life predictors of adult CVD risk than birth weight alone (22). Growth velocity in early postnatal life, particularly rapid "catch-up" growth during the first few months in low-birth-weight infants and weight gain in childhood, strongly affects endothelial function and subsequently the development of atherosclerosis and CVD (22). It has been proposed that childhood weight gain diverts energy disproportionately to adipose tissue, particularly in the abdomen, thereby increasing metabolic load (23). In addition, animal studies have shown that nutritional "mismatch" may occur when intrauterine undernutrition is followed by postnatal overnutrition, especially with energy-dense foods (4).

\section{VASCULAR HEALTH BIOMARKERS, CVD RISK FACTORS, AND CVD RISK IN NONTWIN CHILDREN}

\section{Measures of Vascular Health}

Various measures of vascular health, including carotid intimamedia thickness, pulse wave velocity, flow-mediated vasodilatation, high-sensitivity C-reactive protein, and cell adhesion molecules, have been suggested as valuable biomarkers of vascular health in pediatric epidemiological studies $(10,24)$. Current data have demonstrated that in pediatric populations, adverse changes in these biomarkers are associated with a range of CVD risk factors, including elevated blood pressure, type 1 and 2 diabetes, obesity, and hypercholesterolemia. Therefore, these biomarkers may be useful in the detection of early structural and functional vascular damage in children with increased CVD risk.

The retinal vasculature, another biomarker of vascular health in children, can be directly and noninvasively quantified (25). Data from several adult prospective population-based studies suggest that retinal arteriolar and venular caliber (diameter) changes are predictive of the incidence of CVD, independent of traditional risk factors (26). Limited epidemiological pediatric studies have shown that retinal vessel caliber is associated with CVD risk factors such as elevated blood pressure (27) and adiposity (28). However, the cross-sectional nature of these studies does not allow for causal inferences. A recent study also demonstrates that poor growth in utero may have an adverse influence on retinal vasculature in children (29).

\section{Maternal Environment During Pregnancy and Traditional CVD Risk Factors}

Gestational diabetes, maternal smoking, and maternal obesity are putative early-life predictors of adult CVD. Longitudinal cohort studies have shown that maternal obesity increases the 
risk of metabolic syndrome in offspring during childhood by approximately twofold (30) and that maternal smoking during pregnancy is associated with CVD risk factors (e.g., metabolic syndrome, elevated blood pressure) in offspring (31). In a systematic review and meta-analysis, it was found that prolonged breastfeeding ( $\geq 4 \mathrm{mo}$ ) may be protective against childhood CVD risk factors such as elevated blood pressure (32). However, these effects were mainly observed in small studies, with little evidence from larger studies ( $\geq 1,000$ participants).

\section{CVD BIOMARKERS AND CVD RISK IN TWIN CHILDREN}

Studies of monozygotic (MZ, genetically identical) and dizygotic (DZ, sharing half of their genetic variation) twins provide a natural study design to assess the relative contribution of nature (heredity) and nurture (environment) on the variation of traits and complex diseases, including CVD (33). Twins are inevitably matched for age, closely matched for (shared) prenatal (e.g., length of gestation, maternal nutrition) and postnatal environment (e.g., rearing). Classic twin studies enable partitioning of phenotypic variance within a population into additive genetic (also known as heritability) and shared environmental and nonshared environmental effects, which include factors that are specific to each fetus, umbilical cord, and placenta. Twin studies using phenotype-discordant MZ twins, in particular, are one of the most powerful study designs in epigenetic epidemiology (34).

\section{Do Twins Always Share an Equal Environment?}

Despite having the same mother, twin pairs may experience different intrauterine environments (35). All DZ twins and onethird of MZ twins have separate amnions and chorions, and their placentas may be either separate or fused. The remaining MZ twins are monochorionic (sharing a common chorion and placenta). Roughly $50 \%$ of the twins with separate chorions have fused placentas, resulting in vascular anastomoses in a large proportion of MZ and 5-8\% of DZ twins (36). Such differences in the nutritional "supply line" between mother and each fetus may ultimately result in birth weight discordance.

Twin studies have revealed differing influences of genetic, shared, and nonshared environmental factors on a range of CVD biomarkers. Suggestions that findings from twin studies may not be generalizable have largely been refuted, although differences may exist in very early childhood (37). In addition, the classic twins design can be improved by including nontwin siblings and parents (37).

A small number of twin studies provide consistent evidence that the nonshared intrauterine environment plays a key role in the development of type 2 diabetes and metabolic syndrome, with implications for CVD risk. A study of 104 pairs of 8-y-old twins strongly indicated that a critical factor underlying the association between low birth weight and high blood pressure must involve nonshared environment (38). A recent study also demonstrated an independent within-pair association between smaller birth size and narrower retinal arterioles in both MZ and DZ twin pairs aged 5-14 y (39), supporting the notion that twin-specific supply line factors affect fetal growth and vascular health. In 31 pairs (22 MZ and $9 \mathrm{DZ}$ ) aged 4-12 y, it was shown that lower birth weight is associated with higher systolic blood pressure, endothelial dysfunction, and thicker carotid intima-media thickness (40). A study of $114(53 \mathrm{DZ}$ and $61 \mathrm{MZ})$ adolescent twin pairs by Ijzerman et al found that lower birth weight was associated with insulin resistance, lower high-density lipoprotein levels, and shorter height in both $\mathrm{DZ}$ and $\mathrm{MZ}$ twin pairs, again implicating a large nonshared environmental component in their variation (41). This study also found that low birth weight was associated with blood pressure, total and low-density lipoprotein cholesterol, and fibrinogen within DZ but not MZ twin pairs, suggesting an additional genetic influence on these associations (41). A longitudinal adolescent twin study (125 MZ and $166 \mathrm{DZ}$ pairs) involving 965 families, however, found little evidence of shared environment effects on the variation in lipids, except high-density lipoprotein cholesterol, and only minimal effects of nonshared environment (42). A twin study involving 174 twin pairs showed that maternal alcohol exposure during pregnancy was associated with increased carotid-femoral pulse wave velocity but not with systolic or diastolic blood pressure or child adiposity measures (e.g., BMI) at 9 y (43).

\section{EPIGENETICS AND ITS ROLE IN DEVELOPMENTAL PROGRAMMING OF CVD}

Epigenetics describes mechanisms that stably control gene activity through multiple rounds of cell division (44). The best-understood epigenetic mechanism is DNA methylation of the cytosine base of the CpG dinucleotide (45) (Figure 1). Other epigenetic mechanisms include covalent modification of DNA-packaging histone proteins and noncoding RNA. DNA methylation has context-dependent effects on transcriptional regulation and efficiency; although it is generally associated with a reduction of expression when present in gene promoters, there is emerging evidence that it can have a locationdependent association with expression, elongation, splicing, and silencing of repetitive DNA (45).

Epigenetic change has been strongly implicated as a key mechanism in the early-life origins of CVD (2). In the pre- and early postnatal period, the epigenome is at its most dynamic and may alter in response to environmental stimuli as reviewed by Szyf (46). A number of intrauterine environmental factors (e.g., maternal diet) have been associated with epigenetic modification, providing a plausible mechanistic link between early-life exposures and changes to the epigenome and adult CVD (47). More important, inflammation, the central pathological process involved in atherosclerosis, has also been associated with global hypermethylation (48). Animal studies, for example, a study conducted by Weaver et al. (49), suggest that these epigenetic modifications may be reversible in early life by appropriate pharmacological agents or even targeted dietary interventions.

\section{ANIMAL STUDIES OF ENVIRONMENT-INDUCED EPIGENETIC} PROGRAMMING OF CVD RISK

Animal studies of the early-life origins of CVD have focused on the effect of maternal dietary restriction during gestation on 


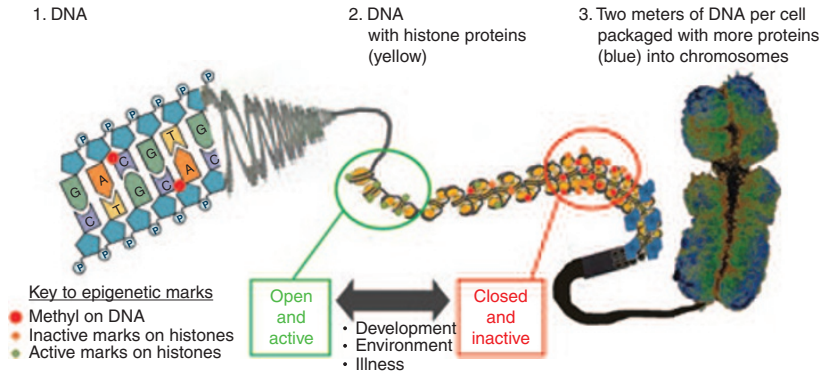

Figure 1. Epigenetic mechanisms: from DNA to chromosomes. In each nucleated cell, DNA is packaged with histone proteins and then further packed with more proteins to form chromosomes. The most commonly studied epigenetic marks, DNA methylation (at the CpG dinucleotide) and histone modifications, which act in concert to influence local DNA packaging, are shown. Combinations of epigenetic marks determine the tightness of this packaging, which in turn influences gene activity via access to the cellular machinery involved in gene transcription and higherorder genomic interaction between regulatory regions such as promoters and enhancers. Regulatory regions can switch between open/active and closed/inactive as part of normal development, in response to environment, or in association with illness.

expression and methylation of key metabolic and cardiovascular regulator genes in tissues such as liver, heart, adrenal gland, and kidney in rats and pigs (50). Offspring exposed to altered maternal nutrition in utero showed modulation of gene expression in adult life associated with subsequent hypertension and dyslipidemia (51). Specific genes showing disrupted DNA methylation include Ppara (peroxisome proliferator-activated receptor- $\alpha$ ), a major regulator of lipid metabolism (50); $\mathrm{Nr3cl}$ (the glucocorticoid receptor), a key regulator of metabolism (50); and Pepck (phosphoenolpyruvate carboxykinase) and Hmgcr (HMG-CoA reductase), which catalyse rate-controlling steps in gluconeogenesis (52) and cholesterol production (50), respectively. These data suggest that dietary change in pregnant mothers alters DNA methylation and gene expression of metabolic regulatory genes in key tissues, which may permanently alter the structure and function of these tissues, causing metabolic and cardiovascular dysfunction and predisposing to later CVD. Similar protein restriction models have also found changes of expression of renin and angiotensin (53), the angiotensin receptor (54), and Dnmt1, a key DNA methylation enzyme (55). Of note, changes in DNA methylation of key upstream regulators have been linked to both altered expression of target genes (Ppara and $\mathrm{Nr} 3 \mathrm{cl}$ ) and concomitant changes in downstream target genes (Aox and Pepck) with subsequent phenotypic changes (hepatic $\beta$-oxidation and gluconeogenesis) $(52,55)$.

\section{HUMAN STUDIES}

A small number of human studies have linked adverse prenatal environment, epigenetic change, and CVD risk. For example, middle-aged offspring of mothers exposed to the Dutch Famine during early pregnancy showed differences in DNA methylation in metabolic and CVD-related candidate genes such as those encoding leptin (LEP) and insulin-like growth factor 2 (IGF2) as compared with their unexposed siblings (47). Although these studies did not link DNA methylation to gene expression, the regions studied are known to correlate with gene expression (47). Offspring exposed to intrauterine malnutrition had a higher adult BMI (56), increased lipids (57), and increased CVD risk (58). Lower maternal carbohydrate intake in early pregnancy was associated with changes in DNA methylation of retinoid receptor- $\alpha(R X R A)$ and endothelial nitric oxide synthase (NOS3) at birth, which in turn correlated with later childhood adiposity (59). The strength of this study is the relationship between RXRA methylation at birth and childhood adiposity and the replication in another cohort. However, no attempts were made to correlate methylation with gene expression. Other gestational CVD risk factors shown to influence DNA methylation in humans include maternal smoking (60), folate intake (61), and levels of homocysteine (62), which is involved in the development of atherosclerosis by inducing changes in DNA methylation in multiple genes in vascular smooth muscle cells and is the biomarker most directly implicated in epigenetic mechanisms relating to CVD risk (2). Epigenetic marks at these genes are sensitive to the prenatal environment (63). Although these studies do not look at whether changes in DNA methylation correlate with changes in gene expression, these data suggest that epigenetic modification is an important underlying mechanism contributing to the link between early-life environment and later CVD risk.

\section{ASSOCIATION OF DNA METHYLATION WITH CVD-RISK FACTORS IN HUMANS}

The mechanistic role of epigenetics in CVD is incompletely understood but is a focus of intense research interest. Genomic DNA isolated from human atherosclerotic lesions is hypomethylated as compared with that of normal tissue (64). More studies are needed to clarify these relationships, although gene-based studies are more likely to lead to the development of appropriate therapeutic agents. In adults, altered DNA methylation at genes including those encoding insulin (INS) and GNAS antisense RNA 1 (GNASAS) is associated with risk of myocardial infarction, although there was no investigation of the effect of altered DNA methylation on gene expression (63). It was also shown recently that childhood obesity is associated with hypermethylation of the proopiomelanocortin $(P O M C)$ gene involved in energy homeostasis and in which genetic polymorphisms are associated with early-onset obesity and adrenal insufficiency (65). Further clues to the mechanisms of type 2 diabetes have come from recent studies showing that transient hypoglycemia can result in a permanent epigenetic change, with altered histone modification associated with changes in gene expression (reviewed by Tonna et al., ref. 66).

These data linking locus-specific epigenetic modification with CVD risk factors are derived largely from epigenetic candidate gene approaches. However, the majority of phenotypic variation due to DNA methylation will not be detected by this approach, and epigenome-wide association studies (EWASs) have recently been advocated (67). No EWAS of CVD per se has been performed. However, a limited number of EWASs have been performed on CVD intermediate phenotypes or risk factors. An EWAS using massively parallel sequencing coupled 
with immunoprecipitation to analyze DNA methylation and histone modification in human aortic endothelial cells exposed to transient hypoglycemia found an association of epigenetic alteration and expression changes in genes involved in metabolic and cardiovascular health (68). A study comparing DNA methylation in pancreatic tissue from five adults with type 2 diabetes who died and 11 matched controls found differential methylation in genes related to $\beta$-cell survival and function (69). The authors found corresponding changes to expression in a subgroup of differentially methylated genes. In whole blood from adults with diabetic nephropathy (as compared with normal controls), several differentially methylated CpG sites in biologically plausible genes were observed (70). Nineteen differentially methylated $\mathrm{CpG}$ sites were observed that associated with diabetic nephropathy. Although no single group of genes stood out, one of the associated genes, UNC13B, whose product binds diacyl glycerol, is associated with diabetic nephropathy. Another recent study using expression and methylation arrays ( 1,500 CpGs with limited genomic coverage) found that DNA methylation in cord blood is associated with altered gene expression, body size, and body composition (71). In addition, Feinberg et al identified four regions of the genome at which DNA methylation covaried with BMI at two time points during adulthood (5). These regions included genes such as that encoding matrix metalloproteinase 9 (MMP9), previously associated with metabolism and obesity. The effect of methylation on gene expression, however, was not examined.

\section{Twin Studies}

As epigenetic modifications such as DNA methylation can be considered quantitative traits (72), twin studies offer a unique opportunity to investigate the heritability of epigenetic modifications. Studies of adult twins have found that at least for a proportion of the genome, DNA methylation can have a high heritability (73). Our findings from the Peri/postnatal Epigenetic Twins Study highlight the influence of nonshared intrauterine environment, genetic variations, and shared environment on epigenomic profile (74-76). Analysis of DNA methylation in $\mathrm{MZ}$ and $\mathrm{DZ}$ pairs revealed that the largest component of variation was attributed to the combined effects of nonshared intrauterine environment and stochastic factors, highlighting the importance of the intrauterine environment on shaping the neonatal epigenome (76). We also used within-pair birth weight discordance to analyze genomic regions at which gene expression (75) and DNA methylation (76) correlated highly with birth weight and such genes were enriched in those associated with CVD risk. These findings show that twins are an ideal model to identify components of variation in DNA methylation at birth and beyond, and enable the differentiation between shared and nonshared environmental influences.

To our knowledge, only one EWAS of a CVD-related phenotype has been performed in twins. Using DNA methylation profiles of purified CD14+ monocytes from 15 type 1 diabetes-discordant pairs of MZ twin children (77), this study revealed the presence of 132 genomic locations that differed in DNA methylation in all twins with type 1 diabetes. Genes associated with these CpGs were enriched in those involved in immune function including HLA-related genes (HLA-DQB1) and regulatory factor X-associated protein (RFXAP), both previously associated with type 1 diabetes in genetic studies, and the proinflammatory cytokine tumor necrosis factor. However, this study is limited by a small sample size, the lack of gene expression data, and the use of whole blood, a tissue for which differential methylation of its cellular constituents could influence overall DNA methylation.

\section{TRANSGENERATIONAL EPIGENETIC INHERITANCE OF CVD}

Epigenetic marks influenced by intrauterine environment are classified as transgenerational epigenetic effects because a maternal environmental factor can have epigenetic effects or even epigenetically independent toxic effects on the developing fetus (offspring or the F1 generation) and, if the fetus is female, on developing germ cells that go on to contribute to the grandchildren (the F2 generation) $(78,79)$. True transgenerational epigenetic inheritance can occur only when environmentally induced epigenetic changes survive the genomewide epigenetic remodeling that accompanies gametogenesis and early postzygotic development, e.g., epigenetic changes observed in the great-grandchildren (the F3 generation) in the example above, as has been demonstrated for rats exposed to endocrine disruptors (80). Transgenerational epigenetic inheritance has been demonstrated in a variety of organisms, such as plants, mice, and fission yeast. Human studies have also pointed to epigenetic inheritance (81), although conclusive evidence is lacking; in such cases, an inherited genetic influence on epigenetics has to be ruled out (82). Circumstantial evidence from human epidemiological studies has shown that smoking or dietary exposures in previous generations are associated with BMI in 9-y-old sons (83) and with adult mortality from CVD and type 2 diabetes (84). A critical exposure time appears to be the prepubertal slow growth period, which coincides with testicular descent and epigenetic reprogramming in merging pools of spermatocytes (85). Direct evidence of transgenerational epigenetic inheritance of CVD-related phenotypes comes from animal studies. Male mice fed a low-protein diet fathered offspring with lower hepatic expression levels of genes involved in lipid and cholesterol biosynthesis, including Ppara, which also exhibited DNA methylation changes (86). Male rats fed a high-fat diet fathered obese sons, who had altered pancreatic gene activity, which at one gene, the interleukin receptor Il13ra2, was accompanied by a large alteration in DNA methylation (87). Furthermore, male pigs fed a diet high in "methylating micronutrients" including folate, vitamin B12, and methionine had leaner grandchildren that also had changes in DNA methylation and gene expression in muscle, liver, and kidney, including the iodotyrosine deiodinase ( $I y d)$ gene involved in thyroid function (88).

\section{ROLE OF EPIDEMIOLOGY IN EPIGENETIC RESEARCH OF CVD}

We have not attempted to cover comprehensively the contribution of epidemiology in defining the role of epigenetics in CVD, which has been the focus of several recent reviews 
(e.g., refs. 89,90). However, a number of important concepts have emerged that need to be taken into account when conducting such studies. Most important, epigenetic changes within an individual can vary over life span, and epigenomic profiles should be considered phenotypes in epigenetic epidemiological designs rather than genotypes. Epigenetic variation can therefore be causal for, or be a consequence of, a trait/disease. It is therefore difficult to establish causality using a large number of associations generated from epigenetic association studies. Longitudinal cohort study designs that have obtained epidemiological data and biological samples from initially disease-free individuals (ideally before or from birth) over the life course could clarify such issues of reverse causality (67). Associations of epigenetics with disease phenotypes may be influenced by confounding (e.g., by socioeconomic status), as can happen with conventional observational epidemiological studies (89). New analytic strategies have been developed to interrogate the causal relationships among environmental exposures, DNA methylation, and outcome. Some of these, if certain conditions are met, utilize genetic variants to act as an instrumental variable to help assess or account for potential confounding (91).

\section{RESEARCH INTO EVIDENCE-BASED INTERVENTIONS}

Animal studies have shown that the epigenome can still be in flux during early postnatal life and that adverse epigenetic modification can be reversed by postnatal diet such as methionine or epigenetic inhibitors such as trichostatin A (49). Furthermore, neonatal leptin treatment can reverse the detrimental effects on offspring health resulting from a maternal high-fat diet (92). A rodent study also showed that offspring fed a postnatal diet enriched with $\omega-3$ fatty acids attenuated prenatally programmed hypertension and hyperleptinemia (93). Such results bode well for future interventions in humans but only after accumulation of evidence from independent laboratories and if humans respond in similar ways as animals. One recent example of cross-cohort validation came from two independent human EWASs that identified changes in the same genes in offspring following exposure to maternal smoking during pregnancy (94). In summary, identification of epigenetic biomarkers in childhood that may predict adult CVD and related diseases could lead to better ways to monitor progress of interventions, whether these are developed through epigenetic knowledge or not.

\section{CONCLUSION}

Identification of epigenetic changes associated with biomarkers of CVD risk in children will offer new opportunities to unravel the underlying biological mechanism of early-life origins of CVD. Longitudinal cohort twin studies, in particular, may contribute to the understanding of the role of epigenetics in the pathogenesis of CVD. As current risk-stratification strategies for CVD are suboptimal, novel early-life CVD-risk biomarkers might improve these strategies, enabling early identification of those at risk and facilitating early-life interventions to alter the risk trajectory and potentially reduce the incidence of CVD later in life.

\section{STATEMENT OF FINANCIAL SUPPORT}

C.S. and P.J.V. are supported by Australian National Health and Medical Research Council (NHMRC) Early Career Research Fellowships. D.P.B. is supported by an NHMRC Clinical Career Development Fellowship. A.-L.P. is supported by an NHMRC Senior Research Fellowship. J.M.C. is supported by the Murdoch Childrens Research Institute. Murdoch Childrens Research Institute research is supported by the Victorian Government's Operational Infrastructure Support Program.

\section{REFERENCES}

1. Mendis S, Puska P, Norrving B, eds. Global Atlas on Cardiovascular Disease Prevention and Control. Geneva: World Health Organization, 2011.

2. Ordovás JM, Smith CE. Epigenetics and cardiovascular disease. Nat Rev Cardiol 2010;7:510-9.

3. Skilton MR, Evans N, Griffiths KA, Harmer JA, Celermajer DS. Aortic wall thickness in newborns with intrauterine growth restriction. Lancet 2005;365:1484-6.

4. Gluckman PD, Hanson MA, Buklijas T. A conceptual framework for the developmental origins of health and disease. J Dev Orig Health Dis 2010;1:6-18.

5. Feinberg AP, Irizarry RA, Fradin D, et al. Personalized epigenomic signatures that are stable over time and covary with body mass index. Sci Transl Med 2010;2:49ra67.

6. Shirodkar AV, Marsden PA. Epigenetics in cardiovascular disease. Curr Opin Cardiol 2011;26:209-15.

7. Napoli C, D'Armiento FP, Mancini FP, et al. Fatty streak formation occurs in human fetal aortas and is greatly enhanced by maternal hypercholesterolemia. Intimal accumulation of low density lipoprotein and its oxidation precede monocyte recruitment into early atherosclerotic lesions. J Clin Invest 1997;100:2680-90.

8. Holman RL, Mcgill HC Jr, Strong JP, Geer JC. The natural history of atherosclerosis: the early aortic lesions as seen in New Orleans in the middle of the of the 20th century. Am J Pathol 1958;34:209-35.

9. Barker DJ. The fetal and infant origins of adult disease. BMJ 1990;301:1111.

10. McNeal CJ, Wilson DP, Christou D, et al. The use of surrogate vascular markers in youth at risk for premature cardiovascular disease. J Pediatr Endocrinol Metab 2009;22:195-211.

11. Touwslager RN, Houben AJ, Gielen M, et al. Endothelial vasodilatation in newborns is related to body size and maternal hypertension. J Hypertens 2012;30:124-31.

12. Singhal A. Endothelial dysfunction: role in obesity-related disorders and the early origins of CVD. Proc Nutr Soc 2005;64:15-22.

13. Morrison JA, Glueck CJ, Horn PS, Yeramaneni S, Wang P. Pediatric triglycerides predict cardiovascular disease events in the fourth to fifth decade of life. Metab Clin Exp 2009;58:1277-84.

14. Dwyer T, Sun C, Magnussen CG, et al. Cohort Profile: The International Childhood Cardiovascular Cohort (i3C) Consortium. Int J Epidemiol 2012; e-pub ahead of print 20 March 2012.

15. Li S, Chen W, Srinivasan SR, et al. Childhood cardiovascular risk factors and carotid vascular changes in adulthood: the Bogalusa Heart Study. JAMA 2003;290:2271-6.

16. Reaven G. Metabolic syndrome: pathophysiology and implications for management of cardiovascular disease. Circulation 2002;106:286-8.

17. Raitakari OT, Porkka KV, Viikari JS, Rönnemaa T, Akerblom HK. Clustering of risk factors for coronary heart disease in children and adolescents. The Cardiovascular Risk in Young Finns Study. Acta Paediatr 1994;83:935-40.

18. Huang RC, Mori TA, Burke V, et al. Synergy between adiposity, insulin resistance, metabolic risk factors, and inflammation in adolescents. Diabetes Care 2009;32:695-701.

19. Chen W, Srinivasan SR, Li S, Xu J, Berenson GS. Clustering of longterm trends in metabolic syndrome variables from childhood to adulthood in Blacks and Whites: the Bogalusa Heart Study. Am J Epidemiol 2007;166:527-33.

20. Cheung YF. Arterial stiffness in the young: assessment, determinants, and implications. Korean Circ J 2010;40:153-62.

21. Hernández MI, Mericq V. Metabolic syndrome in children born small-forgestational age. Arq Bras Endocrinol Metabol 2011;55:583-9. 
22. Eriksson JG, Forsén T, Tuomilehto J, Winter PD, Osmond C, Barker DJ. Catch-up growth in childhood and death from coronary heart disease: longitudinal study. BMJ 1999;318:427-31.

23. Guilloteau P, Zabielski R, Hammon HM, Metges CC. Adverse effects of nutritional programming during prenatal and early postnatal life, some aspects of regulation and potential prevention and treatments. J Physiol Pharmacol 2009;60:Suppl 3:17-35.

24. Urbina EM, Williams RV, Alpert BS, et al.; American Heart Association Atherosclerosis, Hypertension, and Obesity in Youth Committee of the Council on Cardiovascular Disease in the Young. Noninvasive assessment of subclinical atherosclerosis in children and adolescents: recommendations for standard assessment for clinical research: a scientific statement from the American Heart Association. Hypertension 2009;54:919-50.

25. Sun C, Wang JJ, Mackey DA, Wong TY. Retinal vascular caliber: systemic, environmental, and genetic associations. Surv Ophthalmol 2009;54:74-95.

26. Wong TY, Klein R, Couper DJ, et al. Retinal microvascular abnormalities and incident stroke: the Atherosclerosis Risk in Communities Study. Lancet 2001;358:1134-40.

27. Mitchell P, Cheung N, de Haseth K, et al. Blood pressure and retinal arteriolar narrowing in children. Hypertension 2007;49:1156-62.

28. Gopinath B, Baur LA, Teber E, Liew G, Wong TY, Mitchell P. Effect of obesity on retinal vascular structure in pre-adolescent children. Int J Pediatr Obes 2011;6:e353-9.

29. Mitchell P, Liew G, Rochtchina E, et al. Evidence of arteriolar narrowing in low-birth-weight children. Circulation 2008;118:518-24.

30. Boney CM, Verma A, Tucker R, Vohr BR. Metabolic syndrome in childhood: association with birth weight, maternal obesity, and gestational diabetes mellitus. Pediatrics 2005;115:e290-6.

31. Huang RC, Burke V, Newnham JP, et al. Perinatal and childhood origins of cardiovascular disease. Int J Obes (Lond) 2007;31:236-44.

32. Owen CG, Whincup PH, Gilg JA, Cook DG. Effect of breast feeding in infancy on blood pressure in later life: systematic review and meta-analysis. BMJ 2003;327:1189-95.

33. Luft FC. Twins in cardiovascular genetic research. Hypertension $2001 ; 37(2$ Part 2):350-6.

34. Dempster EL, Pidsley R, Schalkwyk LC, et al. Disease-associated epigenetic changes in monozygotic twins discordant for schizophrenia and bipolar disorder. Hum Mol Genet 2011;20:4786-96.

35. Bergvall N, Cnattingius S. Familial (shared environmental and genetic) factors and the foetal origins of cardiovascular diseases and type 2 diabetes: a review of the literature. J Intern Med 2008;264:205-23.

36. Kyvik KO. Generalisability and assumptions of twin studies. In: Spector TD, Snieder H, MacGregor AJ, eds. Advances in Twin and Sib-Pair Analysis. London, UK: Oxford University Press, 2000:67-78.

37. Martin N, Boomsma D, Machin G. A twin-pronged attack on complex traits. Nat Genet 1997;17:387-92.

38. Dwyer T, Blizzard L, Morley R, Ponsonby AL. Within pair association between birth weight and blood pressure at age 8 in twins from a cohort study. BMJ 1999;319:1325-9.

39. Sun C, Ponsonby AL, Wong TY, et al. Effect of birth parameters on retinal vascular caliber: the Twins Eye Study in Tasmania. Hypertension 2009;53:487-93.

40. Halvorsen CP, Andolf E, Hu J, Pilo C, Winbladh B, Norman M. Discordant twin growth in utero and differences in blood pressure and endothelial function at 8 years of age. J Intern Med 2006;259:155-63.

41. Ijzerman RG, Boomsma DI, Stehouwer CD. Intrauterine environmental and genetic influences on the association between birthweight and cardiovascular risk factors: studies in twins as a means of testing the fetal origins hypothesis. Paediatr Perinat Epidemiol 2005;19:Suppl 1:10-4.

42. Middelberg RP, Martin NG, Whitfield JB. A longitudinal genetic study of plasma lipids in adolescent twins. Twin Res Hum Genet 2007;10:127-35.

43. Morley R, Dwyer T, Hynes KL, et al. Maternal alcohol intake and offspring pulse wave velocity. Neonatology 2010;97:204-11.

44. Reik W. Stability and flexibility of epigenetic gene regulation in mammalian development. Nature 2007;447:425-32.

45. Bird A, Tate P, Nan X, et al. Studies of DNA methylation in animals. J Cell Sci Suppl 1995;19:37-9.
46. Szyf M. The dynamic epigenome and its implications in toxicology. Toxicol Sci 2007;100:7-23.

47. Heijmans BT, Tobi EW, Stein AD, et al. Persistent epigenetic differences associated with prenatal exposure to famine in humans. Proc Natl Acad Sci USA 2008;105:17046-9.

48. Libby P, Okamoto Y, Rocha VZ, Folco E. Inflammation in atherosclerosis: transition from theory to practice. Circ J 2010;74:213-20.

49. Weaver IC, Meaney MJ, Szyf M. Maternal care effects on the hippocampal transcriptome and anxiety-mediated behaviors in the offspring that are reversible in adulthood. Proc Natl Acad Sci USA 2006;103: 3480-5.

50. Altmann S, Murani E, Schwerin M, Metges CC, Wimmers K, Ponsuksili S. Dietary protein restriction and excess of pregnant German Landrace sows induce changes in hepatic gene expression and promoter methylation of key metabolic genes in the offspring. J Nutr Biochem 2013;24: 484-95.

51. Bogdarina I, Welham S, King PJ, Burns SP, Clark AJ. Epigenetic modification of the renin-angiotensin system in the fetal programming of hypertension. Circ Res 2007;100:520-6.

52. Burdge GC, Slater-Jefferies J, Torrens C, Phillips ES, Hanson MA, Lillycrop KA. Dietary protein restriction of pregnant rats in the F0 generation induces altered methylation of hepatic gene promoters in the adult male offspring in the F1 and F2 generations. Br J Nutr 2007;97:435-9.

53. Woods LL, Ingelfinger JR, Nyengaard JR, Rasch R. Maternal protein restriction suppresses the newborn renin-angiotensin system and programs adult hypertension in rats. Pediatr Res 2001;49:460-7.

54. McMullen S, Langley-Evans SC. Sex-specific effects of prenatal low-protein and carbenoxolone exposure on renal angiotensin receptor expression in rats. Hypertension 2005;46:1374-80.

55. Lillycrop KA, Slater-Jefferies JL, Hanson MA, Godfrey KM, Jackson AA, Burdge GC. Induction of altered epigenetic regulation of the hepatic glucocorticoid receptor in the offspring of rats fed a protein-restricted diet during pregnancy suggests that reduced DNA methyltransferase-1 expression is involved in impaired DNA methylation and changes in histone modifications. Br J Nutr 2007;97:1064-73.

56. Stein AD, Kahn HS, Rundle A, Zybert PA, van der Pal-de Bruin K, Lumey LH. Anthropometric measures in middle age after exposure to famine during gestation: evidence from the Dutch famine. Am J Clin Nutr 2007;85:869-76.

57. Lumey LH, Stein AD, Kahn HS, Romijn JA. Lipid profiles in middle-aged men and women after famine exposure during gestation: the Dutch Hunger Winter Families Study. Am J Clin Nutr 2009;89:1737-43.

58. Painter RC, de Rooij SR, Bossuyt PM, et al. Early onset of coronary artery disease after prenatal exposure to the Dutch famine. Am J Clin Nutr 2006;84:322-7; quiz 466-7.

59. Godfrey KM, Sheppard A, Gluckman PD, et al. Epigenetic gene promoter methylation at birth is associated with child's later adiposity. Diabetes 2011;60:1528-34.

60. Flom JD, Ferris JS, Liao Y, et al. Prenatal smoke exposure and genomic DNA methylation in a multiethnic birth cohort. Cancer Epidemiol Biomarkers Prev 2011;20:2518-23.

61. Steegers-Theunissen RP, Obermann-Borst SA, Kremer D, et al. Periconceptional maternal folic acid use of 400 microg per day is related to increased methylation of the IGF2 gene in the very young child. PLoS ONE 2009; 4:e7845.

62. Fryer AA, Emes RD, Ismail KM, et al. Quantitative, high-resolution epigenetic profiling of $\mathrm{CpG}$ loci identifies associations with cord blood plasma homocysteine and birth weight in humans. Epigenetics 2011;6:86-94.

63. Talens RP, Jukema JW, Trompet S, et al.; PROSPER Group. Hypermethylation at loci sensitive to the prenatal environment is associated with increased incidence of myocardial infarction. Int $\mathrm{J}$ Epidemiol 2012;41:106-15.

64. Lee ME, Wang H. Homocysteine and hypomethylation. A novel link to vascular disease. Trends Cardiovasc Med 1999;9:49-54.

65. Coll AP, Loraine Tung YC. Pro-opiomelanocortin (POMC)-derived peptides and the regulation of energy homeostasis. Mol Cell Endocrinol 2009;300:147-51. 
66. Tonna S, El-Osta A, Cooper ME, Tikellis C. Metabolic memory and diabetic nephropathy: potential role for epigenetic mechanisms. Nat Rev Nephrol 2010;6:332-41.

67. Rakyan VK, Down TA, Balding DJ, Beck S. Epigenome-wide association studies for common human diseases. Nat Rev Genet 2011;12:529-41.

68. Pirola L, Balcerczyk A, Tothill RW, et al. Genome-wide analysis distinguishes hyperglycemia regulated epigenetic signatures of primary vascular cells. Genome Res 2011;21:1601-15.

69. Volkmar M, Dedeurwaerder S, Cunha DA, et al. DNA methylation profiling identifies epigenetic dysregulation in pancreatic islets from type 2 diabetic patients. EMBO J 2012;31:1405-26.

70. Bell CG, Teschendorff AE, Rakyan VK, Maxwell AP, Beck S, Savage DA. Genome-wide DNA methylation analysis for diabetic nephropathy in type 1 diabetes mellitus. BMC Med Genomics 2010;3:33.

71. Relton CL, Groom A, St Pourcain B, et al. DNA methylation patterns in cord blood DNA and body size in childhood. PLoS ONE 2012;7:e31821.

72. Gibbs JR, van der Brug MP, Hernandez DG, et al. Abundant quantitative trait loci exist for DNA methylation and gene expression in human brain. PLoS Genet 2010;6:e1000952.

73. Schalkwyk LC, Meaburn EL, Smith R, et al. Allelic skewing of DNA methylation is widespread across the genome. Am J Hum Genet 2010;86:196-212.

74. Ollikainen M, Smith KR, Joo EJ, et al. DNA methylation analysis of multiple tissues from newborn twins reveals both genetic and intrauterine components to variation in the human neonatal epigenome. Hum Mol Genet 2010;19:4176-88.

75. Gordon L, Joo JH, Andronikos R, et al. Expression discordance of monozygotic twins at birth: effect of intrauterine environment and a possible mechanism for fetal programming. Epigenetics 2011;6:579-92.

76. Gordon L, Joo JE, Powell JE, et al. Neonatal DNA methylation profile in human twins is specified by a complex interplay between intrauterine environmental and genetic factors, subject to tissue-specific influence. Genome Res 2012;22:1395-406.

77. Rakyan VK, Beyan H, Down TA, et al. Identification of type 1 diabetesassociated DNA methylation variable positions that precede disease diagnosis. PLoS Genet 2011;7:e1002300.

78. Whitelaw NC, Whitelaw E. How lifetimes shape epigenotype within and across generations. Hum Mol Genet 2006;15 Spec No 2:R131-7.

79. Jirtle RL, Skinner MK. Environmental epigenomics and disease susceptibility. Nat Rev Genet 2007;8:253-62.
80. Anway MD, Cupp AS, Uzumcu M, Skinner MK. Epigenetic transgenerational actions of endocrine disruptors and male fertility. Science 2005;308:1466-9.

81. Suter CM, Martin DI, Ward RL. Germline epimutation of MLH1 in individuals with multiple cancers. Nat Genet 2004;36:497-501.

82. Chong S, Youngson NA, Whitelaw E. Heritable germline epimutation is not the same as transgenerational epigenetic inheritance. Nat Genet 2007;39:574-5; author reply 575-6.

83. Pembrey ME, Bygren LO, Kaati G, et al.; ALSPAC Study Team. Sex-specific, male-line transgenerational responses in humans. Eur J Hum Genet 2006;14:159-66.

84. Kaati G, Bygren LO, Edvinsson S. Cardiovascular and diabetes mortality determined by nutrition during parents' and grandparents' slow growth period. Eur J Hum Genet 2002;10:682-8.

85. Gallou-Kabani C, Junien C. Nutritional epigenomics of metabolic syndrome: new perspective against the epidemic. Diabetes 2005;54:1899-906.

86. Carone BR, Fauquier L, Habib N, et al. Paternally induced transgenerational environmental reprogramming of metabolic gene expression in mammals. Cell 2010;143:1084-96.

87. Ng SF, Lin RC, Laybutt DR, Barres R, Owens JA, Morris MJ. Chronic high-fat diet in fathers programs $ß$-cell dysfunction in female rat offspring. Nature 2010;467:963-6.

88. Braunschweig M, Jagannathan V, Gutzwiller A, Bee G. Investigations on transgenerational epigenetic response down the male line in F2 pigs. PLoS ONE 2012;7:e30583.

89. Relton CL, Davey Smith G. Is epidemiology ready for epigenetics? Int Epidemiol 2012;41:5-9.

90. Jablonka E. Epigenetic epidemiology. Int J Epidemiol 2004;33:929-35.

91. Relton CL, Davey Smith G. Two-step epigenetic Mendelian randomization: a strategy for establishing the causal role of epigenetic processes in pathways to disease. Int J Epidemiol 2012;41:161-76.

92. Vickers $\mathrm{MH}$, Gluckman PD, Coveny AH, et al. Neonatal leptin treatment reverses developmental programming. Endocrinology 2005;146: 4211-6.

93. Wyrwoll CS, Mark PJ, Mori TA, Puddey IB, Waddell BJ. Prevention of programmed hyperleptinemia and hypertension by postnatal dietary omega-3 fatty acids. Endocrinology 2006;147:599-606

94. Joubert BR, Håberg SE, Nilsen RM, et al. 450K epigenome-wide scan identifies differential DNA methylation in newborns related to maternal smoking during pregnancy. Environ Health Perspect 2012;120:1425-31. 